\title{
Antithrombotic, Antiaggregant and Anticoagulant Effect of Methanolic Fraction of Calamintha officinalis: In vitro and ex vivo Experiments
}

\author{
Kaoutar Zoheir ${ }^{1}$, Mohamed Bnouham ${ }^{1}$, Abdelkhaleq Legssyer ${ }^{1}$, Abderrahim Ziyyat ${ }^{1}$, \\ Mohammed Berrabah ${ }^{2}$, Mohammed Aziz ${ }^{1}$, Mohammed Bensaid ${ }^{3}$ and Hassane Mekhfi ${ }^{1 *}$ \\ ${ }^{1}$ Laboratory of Physiology, Genetic and Ethnopharmacology, Faculty of Sciences, \\ University Mohammed the First, Oujda, 60000, Morocco; hmekhfi@yahoo.fr \\ ${ }^{2}$ Laboratory of Mineral Solid and Analytical Chemistry, Department of Chemistry, Faculty of Sciences, \\ University Mohammed the First, Oujda 60000, Morocco \\ 3Laboratory Bensaid of Pathological Cytology and Anatomy, 100, Allal Ben Abdellah Street, \\ Apartment number 9, Oujda, 60000, Morocco
}

\begin{abstract}
The objective was to study the effect of Calamintha officinalis methanolic fraction in the prevention of thrombosis and to explore its effect on primary and secondary hemostasis. The antithrombotic activity was evaluated by using the pulmonary thromboembolism experimental model. Platelet aggregation, tail bleeding time and coagulation assays were explored to elucidate the antithrombotic mechanism. For aggregation, washed platelets were incubated in presence of Calamintha officinalis methanolic fraction and then activated by different agonists (thrombin, ADP, collagen). The bleeding time was determined to measure the time between the tail incision and the moment the bleeding stops. The coagulation was explored by measuring prothrombin time, activated partial thromboplastin time, thrombin time and plasmatic fibrinogen concentration. For ex vivo study, the animals were treated by the Calamintha officinalis methanolic fraction $(250 \mathrm{mg} / \mathrm{kg} /$ day) for 4 weeks. Then, platelet aggregation, tail bleeding time and coagulation parameters was studied. The results indicate that $C$. officinalis methanol fraction seems to exert in vivo an antithrombotic action ( $40 \%$ of protection). The in vitro investigations also show that this fraction significantly inhibits aggregation, increases bleeding time, coagulation times and reduces fibrinogen concentration. The chronic treatment of animals confirms the precedent data. This study demonstrates an antithrombotic effect of $C$. officinalis. The observed antiaggregant and anticoagulant effects could explain this activity.
\end{abstract}

Keywords: Bleeding, Calamintha officinalis, Coagulation, Platelet Aggregation, Thrombosis

\section{Introduction}

Thrombosis is a very complicated physiological and physiopathological process of blood clot formation in the arterial or venous circulation. Abnormal platelets hyperactivity linked to arterial hypertension, diabetes plays a key role in the pathogenesis of thrombosis_ which results in obstruction of blood vessels that causes stroke, myocardial and cerebral infarction ${ }_{-}^{2}$. Several drugs are used for their antithrombotic, antiplatelet,

\footnotetext{
${ }^{*}$ Author for correspondence
} 
anticoagulant and fibrinolytic properties, to prevent and treat cardiovascular thrombosis and embolism³. These drugs inhibit the formation and extension of thrombi or promote their disappearance to improve the bloodstream. Excessive bleeding event related to antithrombotic drugs is a major risk by their frequency and severity. Consequently, researches today are moving towards the development of new treatments including natural products that could have an antithrombotic effect, with low bleeding risk. Calamintha officinalis (calment, Lamiaceae family) is an aromatic herb used in cooking and to improve the flavor and fragrance of food. It has been used since ancient times for its medicinal properties. In Morocco, it was often used, in the folk medicine against fever, cough ${ }_{-}^{4}$ and $\operatorname{cold}_{-}^{5}$. Many experimental studies reported that $C$. officinalis has various biological and pharmacological properties, such as enhancing the sleeping time, producing a decrease in body temperature ${ }_{\rightarrow}^{6}$, hypolipidemic, antidiabetic ${ }_{-}^{7}$ and hypoglycaemic activities- ${ }_{-}^{8}$ To our knowledge, this is the first work that explores the effect of $C$. officinalis on hemostasis. The present study mainly focuses to investigate, in first, the antihrombotic activity of methanol fraction C. officinalis (MFCO) and tend to elucidate the mechanism of action by studying in vitro and ex vivo platelet aggregation and plasmatic coagulation process.

\section{Materials and Methods}

\subsection{Methanol Fraction Preparation}

C. officinalis was collected in the region of Tafoughalt (in the Eastern Morocco), identified by Pr. Benyounes HALOUI (Biology Department, Faculty of Sciences, University Mohammed the First, Oujda, Morocco) (Voucher number HUMPOM 350).

The aerial part of the plant was cleaned and dried. Four organic fractions were obtained by reiterated cycles of extractions with increasing polarity of solvents (petroleum ether, dichloromethane, ethyl acetate and methanol) by using a Soxhlet extractor. $100 \mathrm{~g}$ of plant was sprayed into powder and placed into the Soxhlet extractor's cartridge and soaked into $750 \mathrm{ml}$ of organic solvent. The obtained organic fractions were filtered, evaporated at $45^{\circ} \mathrm{C}$ and stored at $-20^{\circ} \mathrm{C}$. The yields of the extraction were $1.2,4.7,1.7$ and $12.0 \%$ respectively for petroleum ether, dichloromethane, ethyl acetate and methanol. The MFCO was selected for the present study because it had the highest yield and the most potent activity (data not shown).

\subsection{Animals}

All studies were optimized on male and female adult Wistar rats and mice. The animals were raised in the biology department under the following conditions: cycles of 12 hours of light followed by 12 hours of darkness in a room temperature of $22^{\circ} \mathrm{C} \pm 2{ }^{\circ} \mathrm{C}$. The animals had constant free access to water and food. All animals used in our experiments were cared for in compliance with the guide for the care and use of laboratory animals, published by the US National Institutes of Health (2011, Guide for the care and use of laboratory animals. $8^{\text {th }}$ Edition). Also, this study was carried out in accordance with Declaration of Helsinki.

\subsection{Acute Toxicity Study}

Oral acute toxicity study of the MFCO was determined on mice weighing 18-25 g. Three groups were formed (ten mice per group, five males and five females). Two groups received two doses of MFCO (5 and $10 \mathrm{~g} / \mathrm{kg}$ respectively), while, the third one received distilled water $(1 \mathrm{ml} / 100 \mathrm{~g})$. All administrations were unique and oral. After treatment, the animals were observed daily for 14 days for all external general symptoms of toxicity, body weight changes and mortality.

\subsection{In vivo Antithrombosis Assay}

The antithrombotic effect of MFCO was performed by using the mouse pulmonary thromboembolism experimental model described by Di Minno and Silver-. Male and female mice (22 to $32 \mathrm{~g}$ ) were divided into three groups (10 mice/group) and were treated orally for seven days. The first group (control) received distilled water $(1 \mathrm{ml} / 100 \mathrm{~g} /$ day $)$, the second was treated with the 
methanol fraction $(250 \mathrm{mg} / \mathrm{kg} /$ day $)$ and the third was treated with acetylsalicylic acid (ASA $30 \mathrm{mg} / \mathrm{kg} /$ day) as a positive control. One hour after the last treatment, the animals were placed into a tailveiner chamber (Bioseb, USA/Canada) and the venous thrombosis was induced by a single injection of a mixture solution containing collagen $(12 \mathrm{mg} / \mathrm{kg})$ and epinephrine $(1 \mathrm{mg} / \mathrm{kg})$ into the lateral tail vein. Immediately after the thrombogenic mixture injection, the animals were observed for 15 minutes. The number of dead and/or paralyzed mice was recorded in each group. The degree of protection against thrombosis in each group was calculated as follows:

$\%$ protection $=[1-($ number of dead and/or paralyzed animals/total animals) $] \times 100$.

\subsection{In vitro Platelet Aggregation}

\subsubsection{Preparation of the Washed Platelets}

The blood sample was removed from rat's $(200-280 \mathrm{~g})$ abdominal aorta after being lightly anesthetized with ether. The blood was collected into tubes containing an anticoagulant solution (1:9 v/v): citric acid 130 $\mathrm{mM}$, trisodium citrate $170 \mathrm{mM}$ and dextrose $4 \%$. The platelets were isolated by a series of centrifugation of blood 10 . The whole blood was centrifuged at $230 \mathrm{~g}$ for 15 minutes to separate the Platelet Rich Plasma (PRP) from the other blood elements. The PRP was collected and then centrifuged at $120 \mathrm{~g}$ for 8 minutes to sediment the residual red blood cells. This PRP was centrifuged at 400 $\mathrm{g}$ for 15 minutes to sediment the platelets. The obtained supernatant Platelet Poor Plasma (PPP) was collected and the platelet pellet was resuspended in a physiological wash buffer ( $\mathrm{NaCl} 137 \mathrm{mM}$; KCl $2.6 \mathrm{mM} ; \mathrm{NaHO}_{3} 12$ $\mathrm{mM} ; \mathrm{MgCl}_{2} 0.9 \mathrm{mM} ; \mathrm{CaCl}_{2} 1.3 \mathrm{mM}$; glucose $5.5 \mathrm{mM}$; gelatin $0.25 \%$; $\mathrm{pH} 6.5)$. After a last centrifugation (400 g, 15 minutes), the platelet pellet was suspended in the adequate volume of final buffer $(\mathrm{NaCl} 137 \mathrm{mM}$; KCl 2.6 $\mathrm{mM} ; \mathrm{MgCl}_{2} 0.9 \mathrm{mM}$; glucose $5.5 \mathrm{mM}$; gelatin $0.25 \%$; Hepes $5 \mathrm{mM} ; \mathrm{CaCl}_{2} 1.3 \mathrm{mM}$; $\mathrm{pH} 7.4$ ), in order to work at a constant platelet concentration, fixed at $5 \times 10^{5}$ cells/ $\mathrm{mm}^{3}$.

\subsubsection{In vitro Platelet Aggregation Assay}

The study goal is to evaluate in vitro the formation of platelet aggregates in absence and presence of MFCO, after their activation by various agonists. The aggregation signal was measured by an aggregometer (Chrono-Log, Aggrometer, PA, USA) coupled to a paper recorder (Leybold-Heraus, Austria). The development of aggregation was visualized by the variation of the light transmission through the platelet suspension. All tests were optimized under constant temperature of $37 \mathrm{C}^{\circ}$ with a $1000 \mathrm{rpm}$ agitation. An aliquot of washed platelets $(250 \mu \mathrm{l})$ was introduced to a cuvette of the aggregometer and pre-incubated for one minute with MFCO at different doses $(0.25,0.5$ and $1 \mathrm{mg} / \mathrm{ml})$. Then, aggregation was triggered by addition of an aggregate agent (ADP $5 \mu \mathrm{M}$, thrombin $0.5 \mathrm{U} / \mathrm{ml}$, collagen $5 \mu \mathrm{g}$ / $\mathrm{ml}$ ) and the signal was recorded for 5 minutes after their stimulation.

The aggregation amount (\%) was measured considering the PPP that presented a light transmission of $100 \%$. The inhibition of platelet aggregation (\%) was measured as follows:

$$
\text { Inhibition }(\%)=[(\mathrm{A}-\mathrm{B}) / \mathrm{A}] \times 100
$$

$A$ : is the maximal aggregation without the MFCO (control), $\mathrm{B}$ : is the maximal aggregation in the presence of the MFCO.

\subsection{In vitro Coagulation Assay}

The anticoagulant activity was determined by measuring the clotting times. PPP was collected after a high-speed centrifugation (460 g for 20 minutes) of the citrated blood and immediately incubated with MFCO for five minutes. Then, an aliquot of the mixture $(50 \mu \mathrm{l})$ was incubated with a specific reagent according to the manufacturer's instruction. The tests were made with a semi-automatic coagulometer (Thrombostat, Behnk Elektronik $\mathrm{GmbH}$ and Co, Germany) under a constant agitation and temperature $\left(37 \mathrm{C}^{\circ}\right)$.

The parameters determined were Prothrombin Time (PT), Activated Partial Thromboplastin Time (APTT), Thrombin Time (TT) and plasmatic fibrinogen 
Antithrombotic, Antiaggregant and Anticoagulant Effect of Methanolic Fraction of Calamintha officinalis: In vitro and ex vivo Experiments

concentration. The PT explores the activity of the coagulation factors in the extrinsic coagulation pathway, the APTT evaluates the progress of the intrinsic coagulation pathways and TT explores the fibrin formation step.

\subsection{Ex vivo Experiments}

\subsubsection{Treatment of Rats}

Twenty Wistar rats weighting 180 to $240 \mathrm{~g}$ were separated into four experimental groups (5 rats per group). Three groups were treated by gavage for four weeks. The first control group received distilled water $(1 \mathrm{ml} / 100 \mathrm{~g} /$ day), the second was treated with MFCO $(250 \mathrm{mg} / \mathrm{kg} /$ day) and the third was treated with a reference antiaggregate drug, ASA (30 mg/kg/day). While, the fourth group received a single dose of warfarin $(1 \mathrm{mg} / \mathrm{kg})$, an anticoagulant reference drug.

\subsubsection{Bleeding Time Determination}

One hour after the last treatment, the animals are anesthetized by pentobarbital $(50 \mathrm{mg} / \mathrm{kg}$ ) and were put on a hotplate thermostatically at $37 \mathrm{C}^{\circ}$. The rat's tail was transacted at the $5 \mathrm{~mm}$ from the tip. As soon as, the blood started flowing, the chronometer was triggered until the bleeding stopped. The blood that flowed was absorbed every 30 seconds with a filter paper. The bleeding time was the duration between the incision and the moment the bleeding stopped.

\subsubsection{Platelet Aggregation Assay}

The ex vivo platelet aggregation was studied immediately after the bleeding time determination of the treated rats. The washed platelets were prepared following the same procedure previously described and the platelet aggregation was directly triggered with the following agonists: ADP $(5 \mu \mathrm{M})$, thrombin $(0.5 \mathrm{U} / \mathrm{ml})$, collagen (5 $\mu \mathrm{g} / \mathrm{ml})$ and arachidonic acid $(20 \mu \mathrm{M})$ and then recorded for 5 minutes.

\subsubsection{Coagulation Times Determination}

In order to optimize the ex vivo coagulation tests, the same procedure was followed as described above in in vitro study.

\subsection{Statistical Analysis}

In the thromboembolism study, the results are expressed as percentage, and compared by Chi-square test. In the other studies, results are expressed as mean \pm S.E.M. The results were compared by Student's t-test. IC $_{50}$ (concentration of $50 \%$ inhibiting aggregation) was calculated using the linear regression method. $\mathrm{p}<0.05$ was considered as statistically significant.

\section{Results}

\subsection{Acute Toxicity}

After oral administration of MFCO at the two doses (5 and $10 \mathrm{~g} / \mathrm{kg}$ ), no mortality was observed and there were no behavioral effects throughout the period of observation.

\subsection{Antithrombotic Activity of Methanolic fraction of $C$. officinalis}

The antithrombotic activity of MFCO was studied in vivo conditions. As shown in Table 1, the oral administration of MFCO at the dose of $250 \mathrm{mg} / \mathrm{kg} /$ day to mice for one week increased moderately the protection against thrombotic events (40\%) when compared to control $(10 \%, \mathrm{p}=0.301)$. As expected, ASA, used as a reference drug, exhibited a significant preventive effect against thrombosis.

\subsection{Effect of $C$. officinalis on Rat Platelet Aggregation in vitro}

Antiaggregant effects were evaluated by incubating the platelet suspension with increasing concentrations of MFCO $(0.25,0.5$ and $1 \mathrm{mg} / \mathrm{ml})$. Platelet aggregation was then triggered by adding thrombin $(0.5 \mathrm{U} / \mathrm{ml})$, ADP $(5 \mu \mathrm{M})$ or collagen $(5 \mu \mathrm{g} / \mathrm{ml})$. The results showed 
Table 1: Effect of methanolic fraction of $C$. officinalis on pulmonary thrombosis in mice

\begin{tabular}{|c|c|c|c|}
\hline & $\begin{array}{c}\text { Distilled water } \\
(1 \mathrm{ml} / 100 \mathrm{~g} / \text { day })\end{array}$ & $\begin{array}{c}\text { a MFCO } \\
(250 \mathrm{mg} / \mathrm{kg} / \text { day })\end{array}$ & $\begin{array}{c}\mathrm{b} \mathrm{ASA} \\
(30 \mathrm{mg} / \mathrm{kg} / \text { day })\end{array}$ \\
\hline $\begin{array}{c}\text { Paralyzed or dead } \\
\text { animals number/total }\end{array}$ & $9 / 10$ & $6 / 10^{\mathrm{NS}}$ & $2 / 10^{* *}$ \\
\hline Protection (\%) & 10 & 40 & 80 \\
\hline
\end{tabular}

${ }^{a}$ MFCO: Methanolic fraction of C. officinalis, ${ }^{b}$ ASA: Acetylsalicylic acid. ${ }^{* *} \mathrm{p}<0.01$, NS: Not significant versus control. The Chi-square test is used to examine the difference between the control and treated groups. Number of independent experiments $=10$.

that MFCO exerts a significant dose-dependent antiaggregate effect (Figure 1). The calculated $\mathrm{IC}_{50}$ values (concentration of 50\% inhibiting aggregation) were 0.4 $\pm 0.03,0.34 \pm 0.05,0.57 \pm 0.07 \mathrm{mg} / \mathrm{ml}$ respectively when aggregation was initiated by thrombin, collagen or ADP $(\mathrm{n}=5)$. The strong antiaggregant activity $(88.6 \%)$ was observed in case of thrombin at $1 \mathrm{mg} / \mathrm{ml}$ of MFCO. Also, ASA a positive control inhibited significantly the platelet aggregation evoked by thrombin when compared to control. The percentage of inhibition was $23.3 \pm 7.97 \%$ (data not show).

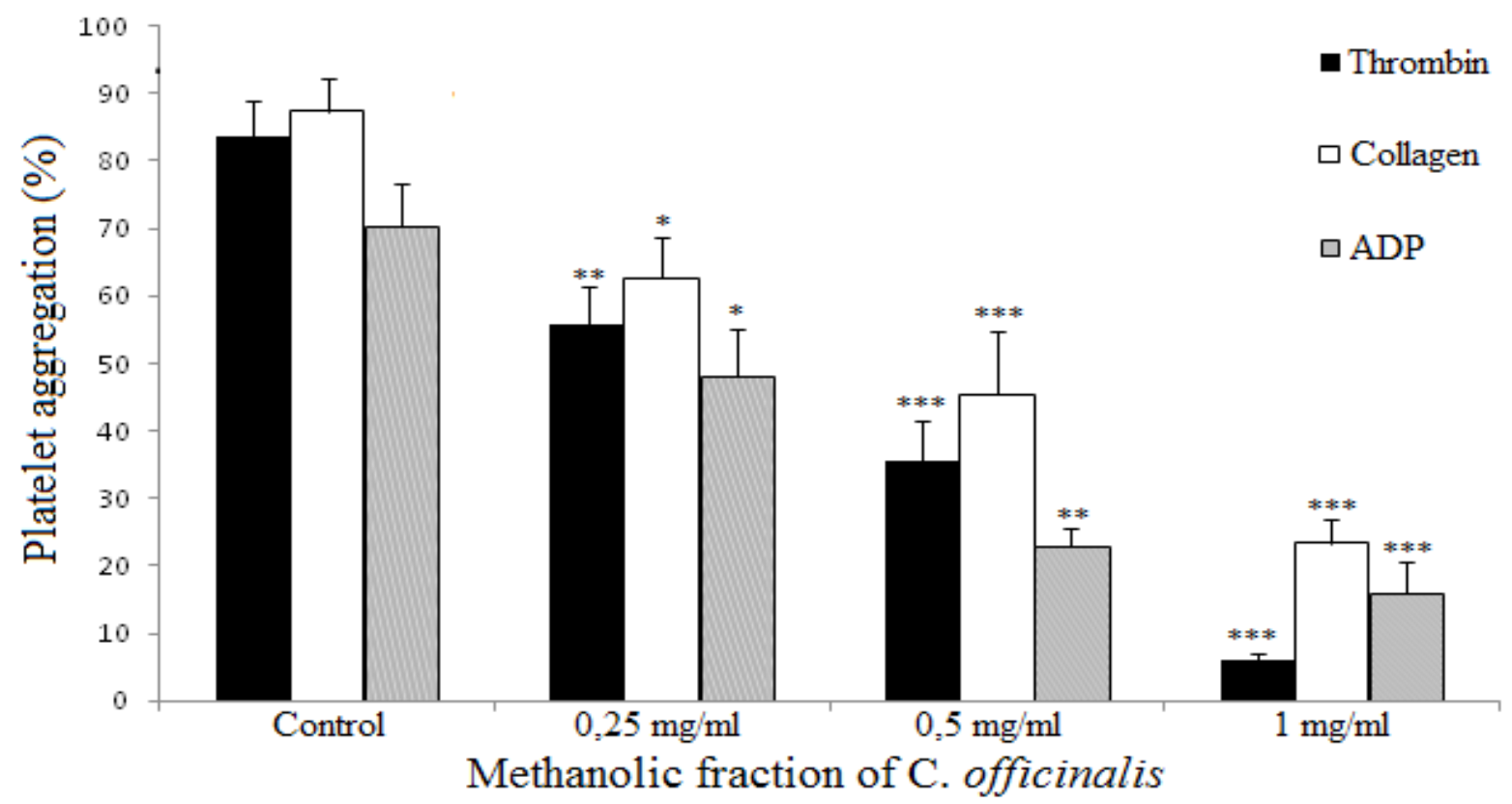

Fig. 1. Dose effect of methanolic fraction of $C$. officinalis on platelet aggregation in vitro induced by thrombin $(0.5 \mathrm{U} / \mathrm{ml})$, collagen $(5 \mu \mathrm{g} / \mathrm{ml})$ and $\operatorname{ADP}(5 \mu \mathrm{M}) .{ }^{*} \mathrm{p}<0.05,{ }^{* *} \mathrm{p}<0.01,{ }^{* * *} \mathrm{p}<0.001$ versus control. Number of independent experiments $=5$. 


\subsection{Effect of $C$. officinalis on Rat Platelet Aggregation ex vivo}

The ex vivo study of MFCO effect on platelet aggregation was monitored to confirm its in vitro inhibitory effect. In pretreated rats, MFCO, at the dose of $250 \mathrm{mg} / \mathrm{Kg} / \mathrm{day}$, showed a significant $(\mathrm{p}<0.01$ and $\mathrm{p}<0.001)$ inhibition of platelet aggregation when induced by arachidonic acid $(20 \mu \mathrm{M})$, ADP $(5 \mu \mathrm{M})$ or thrombin $(0.5 \mathrm{U} / \mathrm{ml})$ (Figure 2$)$. The percentages of inhibition were 67.4, 54.6 and 59.8\% respectively. While, MFCO didn't inhibit significantly the collagen $(5 \mu \mathrm{g} / \mathrm{ml})$ induced platelet aggregation. ASA, being a positive control, inhibited significantly platelet aggregation (Figure 2). The percentage of inhibition varies between 52 and $61 \%$.

\subsection{Effect of $C$. officinalis on Tail Bleeding Time in Rats ex vivo}

The results showed in Table 2 indicated that the chronic treatment by $\mathrm{MFCO}$ at $250 \mathrm{mg} / \mathrm{kg} /$ day for 30 days produced a significant increase $(\mathrm{p}<0.01)$ on bleeding

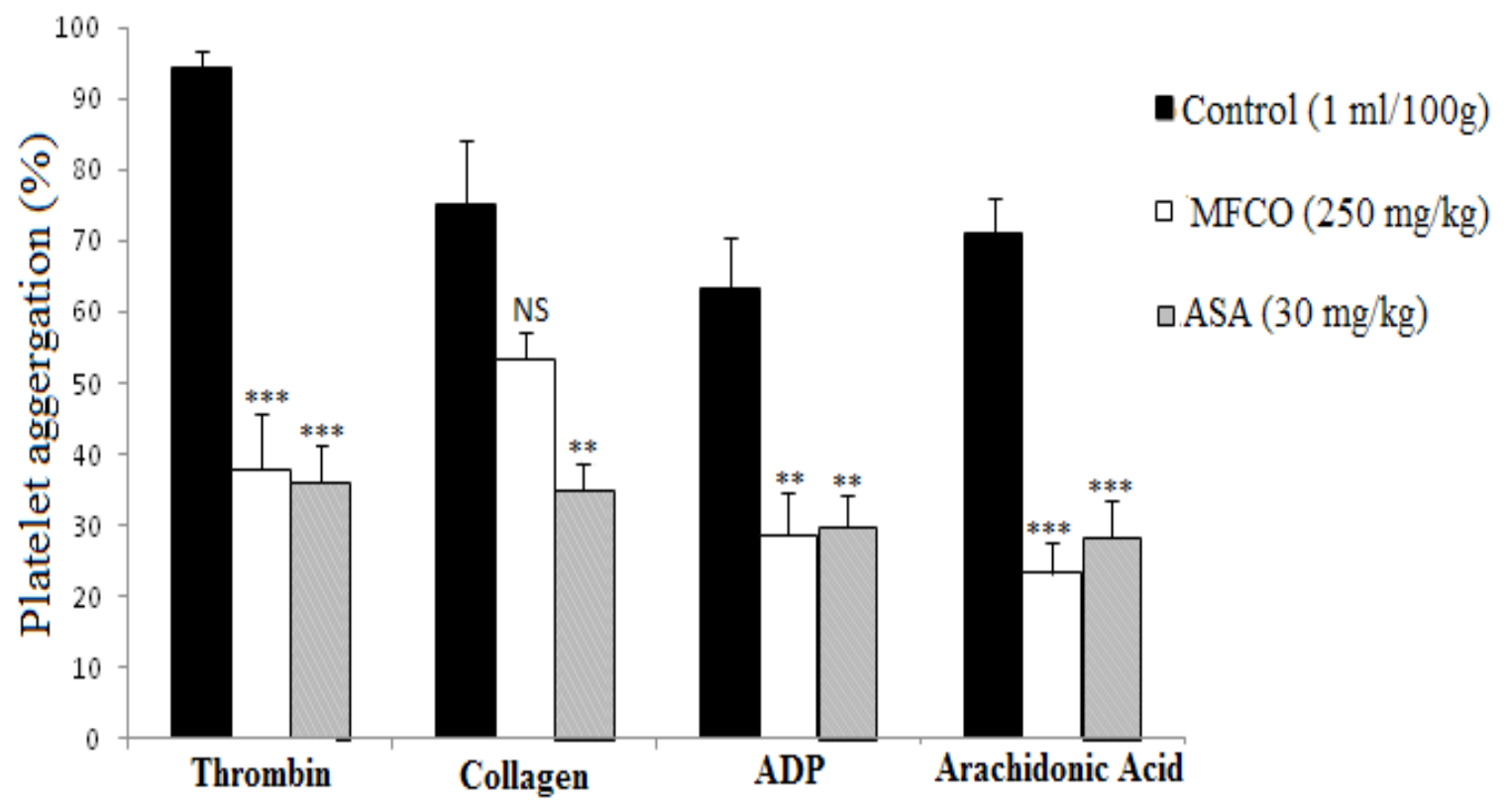

Fig. 2. Effects of chronic treatment by methanolic fraction of $C$. officinalis on rat platelet aggregation induced by thrombin $(0.5 \mathrm{U} / \mathrm{ml})$, collagen $(5 \mu \mathrm{g} / \mathrm{ml}), \operatorname{ADP}(5 \mu \mathrm{M})$ and arachidonic acid $(20 \mu \mathrm{M})$. MFCO: methanolic fraction of Calamintha officinalis ASA: acetylsalicylic acid. ${ }^{* *} p<0.01,{ }^{* * *} p<0.001$, NS: Not significant versus control. Number of independent experiments $=5$.

Table 2: Effects of chronic treatment by methanolic fraction of $C$. officinalis on tail bleeding time

\begin{tabular}{|c|c|c|c|}
\hline & $\begin{array}{c}\text { Distilled water } \\
(1 \mathrm{ml} / 100 \mathrm{~g} / \text { day })\end{array}$ & $\begin{array}{c}{ }^{\mathrm{a}} \mathrm{MFCO} \\
(250 \mathrm{mg} / \mathrm{kg} / \text { day })\end{array}$ & $\begin{array}{c}{ }^{\mathrm{b}} \mathrm{ASA} \\
(30 \mathrm{mg} / \mathrm{kg} / \text { day })\end{array}$ \\
\hline $\begin{array}{c}\text { Bleeding time } \\
\text { (second) }\end{array}$ & $183.7 \pm 10.9$ & $372.0 \pm 40.0^{* *}$ & $292.6 \pm 32.9^{*}$ \\
\hline
\end{tabular}

${ }^{\mathrm{a}}$ MFCO: Methanolic fraction of C. officinalis, ${ }^{\mathrm{b}}$ ASA: Acetylsalicylic acid, ${ }^{*} \mathrm{p}<0.05^{* *} \mathrm{p}<0.01$ versus control. Number of independent experiments $=5$. 
time by approximately $50 \%$ in comparison with the control. ASA, at $30 \mathrm{mg} / \mathrm{kg} /$ day, also significantly prolongs this parameter $(\mathrm{p}<0.05)$.

\subsection{Effect of $C$. officinalis on Coagulation Times in Rats in vitro}

The possible anticoagulant activity of MFCO at different doses $(0.5,1$ and $2 \mathrm{mg} / \mathrm{ml})$ was studied. The results grouped in Table 3 indicate that the MFCO may affect the three coagulation times according to the tested concentration. Indeed, TT starts to increase significantly ( $\mathrm{p}<0.001)$ since $0.5 \mathrm{mg} / \mathrm{ml}$ followed by PT $(\mathrm{p}<0.05)$ at $1 \mathrm{mg} / \mathrm{ml}$ and APTT $(\mathrm{p}<0.05)$ at $2 \mathrm{mg} / \mathrm{ml}$. These modifications were accompanied by a significant decline $(\mathrm{p}<0.01)$ in the fibrinogen concentration at all doses of MFCO. As expected, heparin $(0.4 \mathrm{U} / \mathrm{ml})$, a known anticoagulant drug, exhibited a very strong anticoagulant effect when compared to control.

\subsection{Effect of $C$. officinalis on Coagulation Times in Rats ex vivo}

The chronic treatment of rats by MFCO at $250 \mathrm{mg} / \mathrm{kg} /$ day for 30 days influenced the coagulation parameters. As shown in Table 4, the MFCO prolonged significantly only the TT $(\mathrm{p}<0.05)$ and decreased fibrinogen concentration $(\mathrm{p}<0.001)$, but didn't modified the APTT and PT when compared to control. In positive control group, APTT, PT and TT were significantly prolonged, and the fibrinogen concentration was decreased after a single administration of warfarin $(1 \mathrm{mg} / \mathrm{kg})$.

Table 3: In vitro effect of the methanolic fraction of $C$. officinalis on coagulation times and fibrinogen concentration

\begin{tabular}{|c|c|c|c|c|}
\hline & bPT (s) & CAPTT (s) & dTT (s) & eFIB (g/l) \\
\hline $\begin{array}{c}\text { Distilled } \\
\text { water (ml) } \\
1: 1 \mathrm{v} / \mathrm{v}\end{array}$ & $16.2 \pm 1$ & $19.05 \pm 0.6$ & $44.15 \pm 2.61$ & $0.91 \pm 0.09$ \\
\hline $\begin{array}{c}\text { a MFCO } \\
(0.5 \mathrm{mg} / \mathrm{ml})\end{array}$ & $17.9 \pm 1.2^{\mathrm{NS}}$ & $19.47 \pm 0.2^{\mathrm{NS}}$ & $85.4 \pm 2.98^{* * *}$ & $0.60 \pm 0.08^{* *}$ \\
\hline $\begin{array}{c}\mathrm{MFCO} \\
(1 \mathrm{mg} / \mathrm{ml})\end{array}$ & $20.68 \pm 1.4^{*}$ & $20.07 \pm 4.7^{\mathrm{NS}}$ & $112.3 \pm 1.57^{* * *}$ & $0.57 \pm 0.09^{* *}$ \\
\hline $\begin{array}{c}\mathrm{MFCO} \\
(2 \mathrm{mg} / \mathrm{ml})\end{array}$ & $21.5 \pm 1.1^{*}$ & $27.42 \pm 2.7^{*}$ & $>300$ & $0.53 \pm 0.08^{* *}$ \\
\hline $\begin{array}{c}\mathrm{Heparin} \\
(0.4 \mathrm{U} / \mathrm{ml})\end{array}$ & $53.48 \pm 4.4^{* * *}$ & $>300$ & $>300$ & $0.51 \pm 0.03^{* *}$ \\
\hline
\end{tabular}

${ }^{a}$ MFCO: Methanolic fraction of C. officinalis, bPT: Prothrombin time, ${ }^{c} A P T T$ : Activated partial thromboplastin time, ${ }^{\mathrm{d}} \mathrm{TT}$ : Thrombin time, ${ }^{\mathrm{e}} \mathrm{FIB}$ : Fibrinogen, ${ }^{*} \mathrm{p}<0.05,{ }^{* *} \mathrm{p}<0.01,{ }^{* * *} \mathrm{p}<0.001$, NS: Not significant versus control. $>300$ : Plasma not coagulated. Number of independent experiments $=$ between 4 and 5 . 
Antithrombotic, Antiaggregant and Anticoagulant Effect of Methanolic Fraction of Calamintha officinalis: In vitro and ex vivo Experiments

Table 4: Effect of chronic treatment by methanolic fraction of $C$. officinalis on coagulation times and fibrinogen concentration

\begin{tabular}{|c|c|c|c|c|}
\hline & bPT (s) & cAPTT (s) & ${ }^{\mathrm{d}}$ TT (s) & ${ }^{\mathrm{e}} \mathrm{FIB}(\mathrm{g} / \mathrm{l})$ \\
\hline $\begin{array}{c}\text { Distilled water } \\
1 \mathrm{ml} / 100 \mathrm{~g} / \text { day }\end{array}$ & $20.8 \pm 0,8$ & $14.8 \pm 1.0$ & $40.4 \pm 1.4$ & $2.4 \pm 0.63$ \\
\hline $\begin{array}{c}\text { a MFCO } \\
250 \mathrm{mg} / \mathrm{kg} / \text { day }\end{array}$ & $15.9 \pm 2.3^{\mathrm{NS}}$ & $19.5 \pm 0.7^{\mathrm{NS}}$ & $58 \pm 5.1^{*}$ & $1.5 \pm 0.06^{* * *}$ \\
\hline $\begin{array}{c}\text { Warfarin } \\
1 \mathrm{mg} / \mathrm{kg}\end{array}$ & $32.6 \pm 3.1^{* *}$ & $45.7 \pm 8.1^{* *}$ & $126.8 \pm 8.8^{* * *}$ & $1.6 \pm 0.05^{* * *}$ \\
\hline
\end{tabular}

${ }^{\mathrm{a} M F C O}$ : Methanolic fraction of C. officinalis. ${ }^{\mathrm{b}} \mathrm{PT}$ : Prothrombin time, ${ }^{\mathrm{c} A P T T}$ : Activated partial thromboplastin time, ${ }^{\mathrm{d}} \mathrm{TT}$ : Thrombin time, ${ }^{\mathrm{e}} \mathrm{FIB}$ : Fibrinogen, ${ }^{*} \mathrm{p}<0.05,{ }^{* *} \mathrm{p}<0.01,{ }^{* *} \mathrm{p}<0.001$, NS: Not significant versus control. Number of independent experiments $=5$.

\section{Discussion}

The thrombotic response to vascular injury is critically involved in the occurrence of some vascular diseases complications. Platelets activation and coagulation factors have key roles in hemostasis and thrombus formation. Despite the efficacy of the antithrombotic treatments, these drugs present a major undesirable effect; bleeding and gastrointestinal diseases $\underline{11}$. Recently, several studies have been conducted on development of new natural antithrombotic agents with better efficiency to treat or prevent venous thrombosis. Hence, the aim was assigned to study the antithrombotic activity of MFCO and elucidate the possible mechanism of action.

Acute pulmonary thromboembolis mouse model, a widely known model by scientific community was used in this study. Results demonstrated that the treatment of mice by the MFCO improve the protection against pulmonary thromboembolism. Indeed, the amount of death or paralyzed mice with pulmonary thrombosis decreased after treatment when compared to untreated control group. To understand the mechanism of action of this antithrombotic effect, primary hemostasis (platelet aggregation, bleeding time) and plasmatic coagulation were explored. The results showed that MFCO inhibited in vitro thrombin; collagen or ADP induced platelet aggregation. These results are confirmed in ex vivo when MFCO diminished significantly platelet aggregation measured in response to thrombin, ADP and arachidonic acid. It has been reported that results of in vivo and in vitro tests of antiplatelet aggregation can be different; some agents may have antiplatelet activities in vitro tests but not in vivo 12 . This could be explained by the fact that concentrations tested in vitro cannot always be reached in vivo 13 . The use of different aggregation inducers may help to better understand the mechanistic pathways by which the extract acts. The antiaggregant effect of $C$. officinalis observed with different aggregation inducers (thrombin, ADP, arachidonic acid or collagen) states that many platelet targets of active compounds of plant can be considered such as, respectively, the Protease Activated Receptors (PAR1 and PAR4), P2Y12 receptor, thromboxane A2 receptor, and the glycoprotein Ia-IIa.

Platelet aggregation is a complex process influenced by many elements. According to the earlier reports, platelet activation can be blocked by inhibiting the thrombin, ADP, phosphodiesterase and thromboxane pathways-14. Indeed, it has been shown that green tea catechin inhibited arachidonic acid induced platelet aggregation by the inhibition of $\mathrm{TXA}_{2}$ formation through the suppression of arachidonic acid liberation 
and thromboxane $A_{2}$ synthase $\stackrel{15}{-}$. Other reports have shown that ginsensoside-Rp1 isolated from Panax ginensis inhibit platelet activation induced by collagen via impaired glycoprotein VI signaling pathway- 16 .

Beside of platelet aggregation, bleeding time is a critical parameter to evaluate activity of antithrombotic agent. Previous reports have shown that bleeding time assay is a useful tool for exploring in vivo primary hemostasis $\stackrel{17}{-}$. The current results indicated that MFCO prolonged significantly the bleeding time in mice and rats. As reported in previous similar studies, the inhibition of platelet aggregation can be associated to a prolongation of bleeding time $\stackrel{18,19}{ }$. However, some other studies noted no change in bleeding time when platelet aggregation was suppressed 20,21 .

Plasmatic coagulation is a complex process highly regulated by interaction between platelets, plasma coagulation factors and vessel wall22, initiated by the intrinsic and extrinsic voices and achieved by fibrinogen polymerization to fibrin. Inhibition of this process is an effective way to prevent the pathological thrombus formation. The interactions of MFCO with coagulation factors were evaluated by measuring the clothing times, PT, APTT, TT and determining the plasmatic fibrinogen concentration. PT and APTT were determined to explore the extrinsic ${ }_{-}^{23}$ and the intrinsic coagulation pathways respectively. TT and fibrinogen concentration determinations were conducted to evaluate the ultimate step of the coagulation cascade, characterized by the conversion of the fibrinogen to fibrin by thrombin.

The MFCO, at different concentrations, was found to extend in vitro in all these clotting times and decreased the fibrinogen concentration. Many reports show similar variations such us Dioscorea zingiberensis extract that produce a significant increase on coagulation times in a dose-dependent manner- 24 . These findings let us to suggest that extrinsic and intrinsic coagulation voices were affected by MFCO, probably by inhibiting one or more coagulation factors activities. The extension of TT means inhibition of the fibrin formation. Earlier studies have reported identical effects, such as Umbilicaria esculenta polysaccharide which prolonged significantly APTT, PT and TT in vitro 25 .

In ex vivo study, the treatment by the MFCO prolonged significantly only $\mathrm{TT}$ and decreased the fibrinogen concentration. While, the PT and APTT were not affected, probably; a higher dose is needed to provoke an increase in this tow times, such as in vitro study.

Previous phytochemical investigations of C. officinalis revealed the presence ofa known family's compounds such us alkaloids, triterpens and polyphenols-26. Experimental studies report that such compounds are biologically active on hemostasis process. Indeed, alkaloids isolated from Scolopendra subspinipes mutilans prevent the formation of thrombi, associated with an inhibition of platelet aggregation and coagulation pathways 27 . On the other hand, studies have also showed that tannins from Arbutus unedo inhibited platelet aggregation 28 .

For polyphenols, flavonoids present a large group of natural products, widely distributed in plant, and exhibit an antiaggregant ${ }^{29}$ and antithrombotic activities 30 . Some hypothesis are evoked to explain the antithrombotic activity of polyphenols such us inhibition of key enzymes involved in platelet function; cyclooxygenase and lipo-oxygenase ${ }^{31}$. These enzymes are implicated in the synthesis of platelet activators like thromboxane $\mathrm{A} 2 \stackrel{32}{2}$. It also has been showed that polyphenol stimulate the formation of prostaglandin I2, a strong platelet aggregation inhibitor $\stackrel{33}{-}$.

Other studies have conducted on MFCO indicating the presence of some phenolic acids like chlorogenic acid, caffeic acid, p-coumaric acid 34 . Experiments have showed that caffeic acid inhibited collagen stimulated platelet aggregation by limiting intracellular $\mathrm{Ca}^{2+}$ mobilization $\stackrel{35}{\rightarrow}$ p-Coumaric acid inhibited ADP induced platelet aggregation and diminished thromboxane B2 production 36 . In the same way, chlorogenic acid exerts an antithrombotic and antiplatelet effect ${ }^{37}$. Finally, these findings suggest that the antithrombotic, antiaggregant and anticoagulant activities of MFCO could be attributed, in part, to the phenolic compounds described above. 
Antithrombotic, Antiaggregant and Anticoagulant Effect of Methanolic Fraction of Calamintha officinalis: In vitro and ex vivo Experiments

\section{Conclusion}

Methanolic fraction of C. officinalis exerts an antithrombotic action on experimental model mice. The demonstrated antiaggregant and anticoagulant effects of MFCO may explain in part this action. Other detailed phytochemical and pharmacological investigations must be conducted to identify the bioactive products and to clarify more the mechanism of action.

\section{Conflict of Interest}

The authors declare that they have no conflict of interests.

\section{Acknowledgments}

This work was supported by the "Unité de Recherche Associée au Centre National de Recherche Scientifique et Technique" (URAC-40) Rabat, Morocco and the "Commission Universitaire de Développement" (CUD, Belgium). Authors wish to thank Mr. Mostapha Badraoui for the reliable care of animals breeding and Miss Asmae Amirou for his permanent assistance.

\section{References}

1. El Haouari M, Rosado JA. Platelet function in hypertension. Blood Cells, Mol Dis. 2009; 42(1):3843. PMid: 18829351. https://doi.org/10.1016/j. bcmd.2008.07.003.

2. Nieswandt B, Pleines I, Bender M. Platelet adhesion and activation mechanisms in arterial thrombosis and ischaemic stroke. J Thromb Haemost. 2011; 9(1S):92-104.

3. Ringleb PA. Thrombolytics, anticoagulants, and antiplatelet agents. Stroke. 2006; 37(2):312-3. PMid: $\quad 16410469 . \quad$ https://doi.org/10.1161/01. STR.0000200560.01068.65.

4. El-Hilaly J, Hmammouchi M, Lyoussi B. Ethnobotanical studies and economic evaluation of medicinal plants in Taounate province (Northern
Morocco). J Ethnopharmacol. 2003; 86(2-3):149-58. https://doi.org/10.1016/S0378-8741(03)00012-6.

5. Merzouki A, Ed-derfoufi F, Molero Mesa J. Contribution to the knowledge of Rifian traditional medicine. II: Folk medicine in Ksar Lakbir district (NW Morocco). Fitoterapia. 2000; 71(3):278-307. https://doi.org/10.1016/S0367-326X(00)00139-8.

6. Monforte MT, TzakouO, Nostro A, Zimbalatti V, Galati EM. Chemical composition and biological activities of Calamintha officinalis Moench essential oil. J Med Food. 2011; 14(3):297-303. PMid: 21142949. https:// doi.org/10.1089/jmf.2009.0191.

7. Singh PP, Jha S, Irchhaiya R. Antidiabetic and antioxidant activity of hydroxycinnamic acids from Calamintha officinalis Moench. Med Chem Research. 2012; 21(8):1717-21. https://doi.org/10.1007/ s00044-011-9690-5.

8. Lemhadri A, Zeggwagh NA, Maghrani M, Jouad, H, Michel JB, Eddouks M. Hypoglycaemic effect of Calamintha officinalis Moench in normal and streptozotocin-induced diabetic rats. J Pharm Pharmacol. 2004; 56:795-9. PMid: 15231045. https:// doi.org/10.1211/0022357023510.

9. Di Minno G, Silver MJ. Mouse antithrombotic assay: a simple method for the evaluation of antithrombotic agents in vivo. Potentiation of antithrombotic activity by ethyl alcohol. J Pharmacol Exp Ther. 1983; 225(1):57-60.

10. Tomita T, Umegaki K, Hayashi E. Basic aggregation properties of washed rat platelets: Correlation between aggregation, phospholipid degradation, malondialdehyde and thromboxane formation. J Pharmacol Methods. 1983; 10(1):31-4. https://doi. org/10.1016/0160-5402(83)90012-8.

11. Johansen M. Antiplatelet therapy after aspirininduced upper gastrointestinal bleeding. Tidsskr Nor Laegeforen. 2006; 126(2):2802-4. PMid: 17086221.

12. Asad M, Aslam M, Munir TA, Nadeem A. Effect of Acacia nilotica leaves extract on hyperglycaemia, lipid 
profile and platelet aggregation in streptozotocin induced diabetic rats. J Ayub Med Coll Abbottabad. 2011; 23(2):3-7. PMid: 24800330.

13. Janssen P, Mensink RP, Cox FJ, Harryvan JL, Hovenier R, Hollman PC, Katan MB. Effect of the flavonoids quercetin and apigenin on hemostasis in healthy voluters: Results from an in vitro and a dietary supplement study. Am J Clin Nutr. 1998; 67(2):25562. PMid: 9459373. https://doi.org/10.1093/ ajcn/67.2.255.

14. Sikka P, Bindra VK. Newer antithrombotic drugs. Indian J Crit Care Med. 2010; 14(4):188-95. PMid: 21572750 PMCid: PMC3085220. https://doi. org/10.4103/0972-5229.76083.

15. Son DJ, Cho MR, Jin YR, Kim SY, Park YH, Lee SH, Akiba S, Sato T, Yun YP. Antiplatelet effect of green tea catechins: a possible mechanism through arachidonic acid pathway. Prostaglandins Leukot Essent Fatty Acids. 2004; 71(1):25-31. PMid: 15172681. https:// doi.org/10.1016/j.plefa.2003.12.004.

16. Endale $M$, Lee WM, Kamruzzaman SM, Kim, SD, Park JY, Park MH, Rhee MH, Park TY, Park HJ, Cho JY, Rhee MH. Ginsenoside-Rp1 inhibits platelet activation and thrombus formation via impaired glycoprotein VI signalling pathway, tyrosine phosphorylation and MAPK activation. $\mathrm{Br}$ J Pharmacolo. 2012; 167(1):109-27. PMid: 22471932 PMCid: PMC3448917. https://doi.org/10.1111/ j.1476-5381.2012.01967.x.

17. Dejana E, Villa S, de Gaetano G. Bleeding time in rats: A comparison of different experimental conditions. Thromb Haemost. 1982; 48(1):108-11. https://doi. org/10.1055/s-0038-1657230.

18. Gadi D, Bnouham M, Aziz M, Ziyyat A, Legssyer A, Legrand C, Lafeve FF, Mekhfi H. Parsley extract inhibits in vitro and ex vivo platelet aggregation and prolongs bleeding time in rats. J Ethnopharmacol. 2009; 125(1):170-4. PMid:19467310. https://doi. org/10.1016/j.jep.2009.05.014.
19. Amirou A, Bnouham M, Legssyer A, Ziyyat A, Aziz M, Berrabah M, and Mekhfi H. Effects of Juglans regia root bark extract on platelet aggregation, bleeding time and plasmatic coagulation: In vitro and Ex vivo Experiments. Evid Based Complementary Alternat Med. 2018; $7313517 . \quad$ https://doi. org/10.1155/2018/7313517.

20. Mekhfi H, Gadi D, Bnouham M, Ziyyat A, Legssyer A, Aziz M. Effect of argan oil on platelet aggregation and bleeding time: A beneficial nutritional property. J Complement Integr Med. 2008; 5(1):18. https://doi. org/10.2202/1553-3840.1164.

21. Kamruzzaman SM, Endale M, Oh WJ, Park SC, Kim KS, Hong JH, Kwak YS, Yun BS, Rhee MH. Inhibitory effects of Bulnesia sarmienti aqueous extract on agonist-induced platelet activation and thrombus formation involves mitogen-activated protein kinases. J Ethnopharmacol. 2010; 130(3):61420. PMid: 20558266. https://doi.org/10.1016/j. jep.2010.05.049.

22. Renne T, Nieswandt B, Gailani D. The intrinsic pathway of coagulation is essential for thrombus stability in mice. Blood Cells, Mol Dis. 2006; 36(2):148-51. PMid: 16466946. https://doi. org/10.1016/j.bcmd.2005.12.014.

23. Schulman S, Bijsterveld NR. Anticoagulants and their reversal. Transfus Med Rev. 2007; 21(1):3748. PMid: 17174219. https://doi.org/10.1016/j. tmrv.2006.08.002.

24. Li H, Huang W, Wen Y, Gong G, Zhao Q, Yu G. Antithrombotic activity and chemical characterization of steroidal saponins from Dioscorea zingiberensis C.H. Wright. Fitoterapia. 2010; 81(8):1147-56. PMid: 20659537. https://doi.org/10.1016/j. fitote.2010.07.016.

25. Wang Y, Shao J, Yao S, Zhang S, Yan J, Wang H, Chen Y. Study on the antithrombotic activity of Umbilicaria esculenta polysaccharide. Carbohydr Polym. 2014; 105(1):231-6. PMid: 24708975. https:// doi.org/10.1016/j.carbpol.2014.01.082. 
Antithrombotic, Antiaggregant and Anticoagulant Effect of Methanolic Fraction of Calamintha officinalis: In vitro and ex vivo Experiments

26. Singh PP, Jha S, Irchhaiya R. Pharmacognostical and physicochemical investigation of the leaf of Calamintha officinalis moench. Asian Pac J Trop Biomed. 2012; 2(3S):S1362-6. https://doi. org/10.1016/S2221-1691(12)60417-1.

27. Lee W, Lee J, Kulkarni R, Kim MA, Hwang JS, Na $\mathrm{M}$, Bae JS. Antithrombotic and antiplatelet activities of small-molecule alkaloids from Scolopendra subspinipes mutilans. Sci Rep. 2016; 6(1):21956. PMid: 26905699 PMCid: PMC4764974. https://doi. org/10.1038/srep21956.

28. Mekhfi H, El Haouari M, Bnouham M, Aziz M, Ziyyat A, Legssyer A. Effects of extracts and tannins from Arbutus unedo leaves on rat platelet aggregation. Phytother Res. 2006; 20(2):135-9. PMid: 16444667. https://doi.org/10.1002/ptr.1822.

29. El Haouari M, Mekhfi H. Antiplatelet aggregation effects of extracts from Arbutus unedo leaves. Plant Science Today. 2017; 4(2):68-74.

30. Quiñones M, Miguel M, Aleixandre A. Beneficial effects of polyphenols on cardiovascular disease. Pharmacol Res. 2013; 68(1):125-31. PMid:23174266. https://doi.org/10.1016/j.phrs.2012.10.018.

31. Middleton E Jr, Kandaswami C, Theoharides TC. The effects of plant flavonoids on mammalian cells: Implications for inflammation, heart disease and cancer. Pharmacol Rev. 2000; 52(4):673-751. PMid: 11121513.

32. Kundu JK, Shin YK, Kim SH, Surh YJ. Resveratrol inhibits phorbol ester-induced expression of COX-2 and activation of NF-kB in mouse skin by blocking IkB kinase activity. Carcinogenesis.
2006; 27(7):1465-74. PMid: 16474181. https://doi. org/10.1093/carcin/bgi349.

33. Manna SK, Mukhopadhyay A, Aggarwal BB. Resveratrol suppresses TNF-induced activation of nuclear transcription factors NF- B, activator protein-1 and apoptosis: Potential Role of Reactive Oxygen Intermediates and Lipid Peroxidation. J Immunol. 2000; 164(12):6509-19. PMid: 10843709. https://doi.org/10.4049/jimmunol.164.12.6509.

34. Monforte MT, Lanuzza F, Pergolizzi S, Mondello F, Tzakou O, Galati EM. Protective effect of Calamintha officinalis moench leaves against alcohol-induced gastric mucosa injury in rats. Macroscopic, histologic and phytochemical analysis. Phytother Res. 2012; 26(6):839-44. PMid: 22076933. https:// doi.org/10.1002/ptr.3647.

35. Lee DH, Kim HH, Cho HJ, Bae JS, Yu YB, Park HJ. Antiplatelet effects of caffeic acid due to $\mathrm{Ca} 2+$ mobilization inhibition via cAMPdependent inositol-1, 4, 5-trisphosphate receptor phosphorylation. J Atheroscler Thrombosis. 2014; 21(1):23-37. PMid:24088646. https://doi. org/10.5551/jat.18994.

36. Luceri C, Giannini L, Lodovici M, Antonucci E, Abbate R, Masini E, Dolara P. p-Coumaric acid, a common dietary phenol, inhibits platelet activity in vitro and in vivo. Br J Nutr. 2007; 97(3):45863. PMid: 17313706. https://doi.org/10.1017/ S0007114507657882.

37. Fuentes E, Caballero J, Alarcon M, Rojas A, Palomo I. Chlorogenic acid inhibits human platelet activation and thrombus formation. PloS one. 2014; 9(3):e90699, 1-13. 